\title{
Using Amplified Fragment-length Polymorphisms (AFLPs) to Identify Peach Cultivars
}

\author{
Maria José Aranzana ${ }^{1}$ \\ IRTA-Departament de Genètica Vegetal, Carretera de Cabrils s/n, 08348 Cabrils (Barcelona), Spain \\ Joaquim Carbó \\ IRTA-Fundació Mas Badia, Carretera de la Tallada s/n, 17134 La Tallada d'Empordà (Girona), Spain \\ Pere Arús ${ }^{2}$ \\ IRTA-Departament de Genètica Vegetal, Carretera de Cabrils s/n, 08348 Cabrils (Barcelona), Spain
}

\begin{abstract}
AdDITIONAL INDEX wORDS. peach, nectarine, molecular markers, AFLPs, SSRs, genetic variability
Abstract. A sample of 210 cultivars of Prunus persica (L.) Batsch, with a wide range of fruit and plant characteristics, was studied for variability using nine polymorphic amplified fragment length polymorphism (AFLP) primer combinations. Forty-seven AFLPs allowed identification of $196(93 \%)$ different genotypes, 187 of which could be distinguished with three primer combinations. Eleven cultivars with the same AFLP phenotype corresponded to known somatic mutations (sports), but from the four sports of the 'Springcrest' group, two ('Maycrest' and 'Queencrest') differed at three AFLPs from the others ('Starcrest' and 'Early Maycrest'). Cluster analysis allowed differentiation of most cultivars with nonmelting fruit flesh, generally used for canning, from the melting-flesh peach and nectarine cultivars used for fresh consumption.
\end{abstract}

Peach [Prunus persica (L.) Batsch] is characterized by a rapid cultivar turnover compared to the slower pace of cultivar replacement in other tree fruit crops. Due to the high economic value of new cultivars, peach breeders, merchants and growers are interested in fast, reliable and highly discriminatory methods that complement, or substitute, for the usually long-term assays needed for cultivar characterization based on morphological determinations.

Molecular markers have been used to study variability among different peach cultivars. The first results were obtained with isozyme genes (Messeguer et al., 1987), which were inefficient for this purpose because of the low number of detectable markers and low level of variability of the species (Arulsekar et al., 1986; Byrne, 1990). DNA-based markers are much more powerful due to the virtually unlimited number of polymorphisms detected. Use of random amplified polymorphic DNA (RAPD) markers (Vinatzer et al., 1999; Warburton and Bliss, 1996) and microsatellite, or simple-sequence repeat (SSR), markers (Aranzana et al., 2002, 2003; Testolin et al., 2000) represented a major improvement and allowed a more complete classification of cultivars.

Amplified fragment length polymorphism (AFLP) markers were proposed by Vos et al. (1995) and have since been used extensively for variability analysis and cultivar identification due to their effectiveness in detecting polymorphic markers, higher reproducibility compared to RAPDs and lower development costs compared to microsatellites (Pejic et al., 1998; Powell et al., 1996; Russell et al., 1997). They were used successfully in a sample of 56 peach cultivars by Dirlewanger et al. (1998). In this paper we study AFLP variation of a large collection (210) of

Received for publication 14 Nov. 2002. Accepted for publication 5 May 2003. This work was supported financially in part by funds from INIA (Instituto Nacional de Investigación y Tecnología Agraria y Alimentaria) SC97-097 and RTA01-118-C2-2 projects and by the contract between Selección Plantas Sevilla S.L. and IRTA. MJA scholarship was provided by the Centre de Referència en Biotecnologia (CeRBa) of the Catalan Government. The authors wish to acknowledge Patrick M. Hayes and Antonio Martín for reviewing the manuscript.

${ }^{1}$ Current address: University of Southern California.

${ }^{2}$ Corresponding author; e-mail pere.arus@irta.es. commercial cultivars of peach and nectarine from modern breeding programs currently grown in Europe and in North and South America, plus some nonmelting flesh cultivars grown for canning but also eaten fresh in Spain. Analysis of this large sample gives a more accurate assessment of the value of these markers for DNA fingerprinting and additional information on the distribution of genetic variability in this important fruit crop.

\section{Materials and methods}

Young leaves were harvested from 210 P. persica cultivars (Table 1). All have been studied previously for variability using 16 SSR loci (Aranzana et al., 2003). One hundred and seventy one cultivars were obtained from the collection of IRTA-Fundació Mas Badia (Girona, Spain), 11 from Maria Luisa Badenes (IVIA, Valencia, Spain), 10 from Ignasi Batlle(IRTA-Fundació Mas Bové, Tarragona, Spain) and 18 from the Spanish company 'Selección Plantas Sevilla S.L.' . Pedigree information was obtained from the Handbook of Peach and Nectarine Varieties by Okie (1998).

The DNA extraction from young leaves was as described by Viruel et al. (1995). AFLP analysis was performed with the following procedure (Vos et al., 1995): One hundred nanograms of peach DNA were first digested with $12 \mathrm{U}$ of EcoRI and $8 \mathrm{U}$ of $M s e \mathrm{I}$ in a volume of $35 \mu \mathrm{L}$ with digestion buffer $(10 \mathrm{~mm}$ Tris-acetate $\mathrm{pH} 7.5,10 \mathrm{~mm}$ magnesium acetate, $50 \mathrm{~mm}$ potassium acetate and 5 mм DTT). Then, fragments were ligated to EcoRI (5 pMol) and $M s e \mathrm{I}(50 \mathrm{pMol})$ adaptors, with $1.6 \mathrm{~mm}$ ATP and $1.4 \mathrm{U}$ of T4 DNA-ligase in the digestion buffer described above. Products were diluted 1:5 with $\mathrm{H}_{2} \mathrm{O}$. PCR reactions were set up with $5 \mu \mathrm{L}$ of diluted restriction-ligation DNA, $30 \mathrm{ng}$ of EcoRI and MseI adaptor-homologous primers each possessing one additional selective nucleotide (EcoRI+A, MseI+C), $0.2 \mathrm{~mm}$ of each dNTP and $0.45 \mathrm{U}$ of Taq polymerase in $1 \times \mathrm{PCR}$ buffer $(10 \mathrm{~mm}$ Tris- $\mathrm{HCl} \mathrm{pH} \mathrm{8.3,} 2.5$ $\mathrm{mm} \mathrm{MgCl}, 50 \mathrm{~mm} \mathrm{KCl}$ and $0.001 \%$ gelatin). Amplification was performed in a thermal cycler (PE9600; Perkin Elmer-Applied Biosystems) with the following cycle profile: $1 \mathrm{~min}$ at $94^{\circ} \mathrm{C}, 28$ cycles of $30 \mathrm{~s}$ at $94^{\circ} \mathrm{C}, 1 \mathrm{~min}$ at $60{ }^{\circ} \mathrm{C}$ and $1 \mathrm{~min}$ at $72^{\circ} \mathrm{C}$, and a final extension of 5 min at $72{ }^{\circ} \mathrm{C}$. Products were diluted $1: 15$ 
Table 1. Cultivars studied and their main characteristics.

\begin{tabular}{|c|c|c|c|c|c|c|c|c|}
\hline Cultivar & Trait ${ }^{2}$ & Origin & Cultivar & Trait & Origin & Cultivar & Trait & Origin \\
\hline Alexandra & PWM & USA & Flordastar & PYM & USA & Royal Giant & NYM & USA \\
\hline Aline & PWM & USA & Glady's & PWM & USA & Royal Glory & PYM & USA \\
\hline Andross & PYN & USA & Glenna & PWM & USA & Royal Moon & PYM & USA \\
\hline Armking & NYM & USA & Gorga & PYN & Spain & Royal Prince & PYM & USA \\
\hline Armking 2 & NYM & USA & Gratia & PWM & USA & Ruby Gem & NWM & USA \\
\hline Armking 3 & NYM & USA & Hardired & NYM & Canada & Ruby Rich & PYM & USA \\
\hline Auberge & PYN & Spain & Hermione & PWM & USA & Sarah & PWM & France \\
\hline Auberge Blanc & PYN & Spain & Independence & NYM & USA & San Lorenzo & PYN & Spain \\
\hline Auberge Ferran & PYN & Spain & Isabella D'Este & PWM & Italy & Seduction & PYM & France \\
\hline Auberge Marino & PYN & Spain & Jeronimo & PYN & Spain & Sensation & PYM & France \\
\hline August Orebrad & NYN & USA & Jesca & PYN & Spain & September Orebrad & NYM & USA \\
\hline August Queen & NWM & Italy & July Lady & PYM & USA & September Queen & NWM & Italy \\
\hline Aurora Grand & NYM & USA & June Crest & PYM & USA & Sibelle & PYM & France \\
\hline Autumn Free & NYM & USA & June Lady & PYM & USA & Silver Belle & NWM & USA \\
\hline Babygold 8 & PYN & USA & Kay Grand & NYM & USA & Silver Gem & NWM & USA \\
\hline Babygold 7 & PYN & USA & Lamone & PYN & Italy & Silver King & NWM & France \\
\hline Betty & PWM & USA & Large White & PWM & USA & Silver Late & NWM & USA \\
\hline Big Top & NYM & USA & Lisbeth & PYM & USA & Silver Ray & NWM & Italy \\
\hline Bigsun & PYFM & France & Lucie & PYM & USA & Silver Rome & NWM & Italy \\
\hline Binaced & PWN & Spain & Maria Aurelia & NYM & Italy & Silver Star & NWM & Italy \\
\hline Bolero & PYM & Italy & Maria Bianca & PWM & Italy & Silvery & NWM & USA \\
\hline Calabacero & PYN & Spain & Maria Delizia & PWM & Italy & Sirio & NYM & Italy \\
\hline Calante & PYN & Spain & Maria Emilia & NYM & Italy & Snow Queen & NWM & USA \\
\hline Canongi & PYN & Spain & Maria Laura & NYM & Italy & Snowred & NWM & France \\
\hline Carolina & NYM & USA & Maruja & PYN & Spain & Snowflame & PYM & USA \\
\hline Carson & PYN & USA & Maybelle & NYM & USA & Spring Bright & NYM & USA \\
\hline Casaboi & PWM & USA/Spain & Maycrest & PYM & USA & Spring Lady & PYM & USA \\
\hline Casarob & PWM & USA/Spain & MB-3 & PWN & Spain & Spring Red & NYM & USA \\
\hline Casasil & NWM & USA/Spain & Melodie & PYM & Italy & Springbelle & PYM & Italy \\
\hline Catherina & PYN & USA & Michelini & PWM & Italy & Starcrest & PYM & France \\
\hline Cofrentes-3 & PYN & Spain & Mid Silver & NWM & USA & Stark Redgold & NYM & USA \\
\hline Cofrentes-5 & PYN & Spain & Moon Grand & NYM & USA & Starlite & PWM & USA \\
\hline Cofrentes- 6 & PYN & Spain & Morsiani 51 & NYM & Italy & Summer Grand & NYM & USA \\
\hline Corine & PYM & France & N-1534/70 & NYM & USA & Summer Lady & PYM & USA \\
\hline Cotigua & PYM & Spain & Nectaross & NYM & Italy & Summer Rich & PYM & USA \\
\hline Cresthaven & PYM & USA & Niagara & NYM & USA & Suncrest & PYM & USA \\
\hline Crimson Lady & PYN & USA & NJC-97 & PYN & USA & Super Crimson Gold & NYM & USA \\
\hline Cristalrose & NYM & France & NJN-76 & NYN & USA & Superqueen & NWM & Italy \\
\hline Daisy & PWM & USA & O'Henry & PYM & USA & Superstar & NYM & USA \\
\hline Delice & PYM & France & P-1319 & PYM & USA & Sweet Cap & FWM & France \\
\hline Dellys & NWM & France & P-86-124 & PWM & USA & Sweet Lady & NYM & Italy \\
\hline Dolores & PWM & USA & P-88-206 & PWM & USA/Spain & Sweet Red & NYM & Italy \\
\hline Douceur & PWM & France & Pacific Star & NYM & USA & Symphonie & PYM & France \\
\hline Duchessa d'Este & PWM & Italy & Paraguayo Delfin & FPN & Spain & Tardibelle & PYM & France \\
\hline Early Giant & NYM & USA & Peret & PYN & Spain & Tasty Free & NYM & USA \\
\hline Early Maycrest & PYM & USA & Peret Ferran & PYN & Spain & Tendresse & PWM & France \\
\hline Early O'Henry & PYM & USA & Peret Marino & PYN & Spain & Tirrenia & PYN & Italy \\
\hline Early Orebrad & NYM & USA & Perfect Delight & NYM & Italy & Top Lady & PYM & USA \\
\hline Early Sun Grand & NYM & USA & Queencrest & PYM & USA & Topcrest & PYM & USA \\
\hline Elegant Lady & PYM & USA & Queen Giant & NWM & USA & Venus & NYM & Italy \\
\hline Escarolita & PYN & Spain & Queen Lady & PYM & USA & Villa Ada & PYN & Italy \\
\hline Escarolita Ferran & PYN & Spain & Queen Ruby & NWM & USA & Villa Doria & PYN & Italy \\
\hline Etoile & PYM & France & Red Coast & PYM & Italy & Villa Giulia & PYN & Italy \\
\hline Evaisa & PYN & Spain & Red Delight & NYM & USA & Vistarich & PYM & USA \\
\hline Fairlane & NYM & USA & Red Diamond & NYM & USA & Voluptia & PWM & Italy \\
\hline Fantasia & NYM & USA & Red Fair & NYM & USA & Weinberger & NYM & Italy \\
\hline Fantasie & PYM & France & Red Moon & PYM & Italy & Weinberger 5199 & PYM & Italy \\
\hline Federica & PYN & USA/Italy & Red Pearl & NYM & USA & White Lady & PWM & USA \\
\hline Festina & NWM & France & Red Silver & NWM & USA & Zee Glo & NYN & USA \\
\hline Fidelia & PWM & USA & Redtop & PYM & USA & Zee Lady & PYM & USA \\
\hline Fidelia Ruth & NWM & Spain & Red Valley & PYM & Italy & Zincal 5 & NYM & USA \\
\hline Fire Gold & NYM & USA & Redhaven & PYM & USA & Zinebel & NYM & USA \\
\hline Fire Red & PYM & USA & Redwing & PWM & USA & Zinege & NWM & USA \\
\hline Fireking & NYM & USA & Rich Lady & PYM & USA & Zinepre & NYM & USA \\
\hline Flaminia & PYM & Italy & Rich May & PYM & USA & Zisearl & NYM & USA \\
\hline Flavor Crest & PYM & USA & Rome Star & PYM & Italy & Zisecan & PYM & USA \\
\hline Flavor Gold & NYM & USA & Romea & PYN & Italy & Zisemay & PYM & USA \\
\hline Flavortop & NYM & USA & Rose Diamond & NYM & USA & Zisesil & NWM & USA \\
\hline Flavour Giant & NWM & USA & Rosired 3 & PYM & Italy & Zisesun & NYM & USA \\
\hline Flordaking & PYM & USA & Royal Gem & PYM & USA & $86-6$ & NYN & USA \\
\hline
\end{tabular}

${ }^{2}$ First letter: $\mathrm{P}=$ peach, $\mathrm{N}=$ nectarine, $\mathrm{F}=$ flat peach. Second letter: $\mathrm{W}=$ white, $\mathrm{Y}=$ yellow. Third letter: $\mathrm{N}=$ nonmelting flesh, $\mathrm{M}=$ melting flesh. 
with water. Selective amplification was achieved with EcoRI and MseI primers having two or three additional nucleotides. EcoRI primers were labeled either with 6-carboxyfluorescein (6-FAM), 2',7'-dimethoxy-4',5'-dichloro-6-carboxy fluorescein (JOE), or 7-trichloro-5-carboxyfluorescein (NED), while the MseI primers were unlabelled. PCR reactions were carried out using $2.5 \mu \mathrm{L}$ of diluted preamplified DNA, $2.5 \mathrm{ng}$ of $E c o \mathrm{RI}+2 /+3$ primer and $15 \mathrm{ng}$ of $M s e \mathrm{I}+3$ primers, $0.1 \mathrm{~mm}$ of each dNTP, $0.225 \mathrm{U}$ of Taq Polymerase in $1 \times$ PCR buffer. Amplification conditions were a first cycle of $2 \mathrm{~min}$ at $94{ }^{\circ} \mathrm{C}, 30 \mathrm{~s}$ at $65^{\circ} \mathrm{C}$ and $2 \mathrm{~min}$ at $72{ }^{\circ} \mathrm{C}$, followed by eight more cycles of a $1{ }^{\circ} \mathrm{C}$ decreasing annealing temperature per cycle and 23 cycles more of $1 \mathrm{~s}$ at $94{ }^{\circ} \mathrm{C}, 30 \mathrm{~s}$ at a temperature of $56{ }^{\circ} \mathrm{C}$ and $2 \mathrm{~min}$ at $72{ }^{\circ} \mathrm{C}$. The reaction was finished with an extension at $60{ }^{\circ} \mathrm{C}$ during $30 \mathrm{~min}$.

The nine AFLP primer combinations (EcoRI/MseI) studied were AAC/CAA (referred to as C41), ACC/CTG (C33), ACC/ CTT(C8B), ACC/CAT(C3B),AG/CAA(C19), ACA/CAA(C29), ACA/CTA(C25),ACA/CAT (C27) and ACA/CAC (C26).AFLPs were named with the code of the primer combination followed by a dash and the number of base pairs of the amplified fragment (i.e., C26-183). Amplified products were mixed with $0.25 \mu \mathrm{L}$ of Gene Scan 500 ROX internal lane standard and $12 \mu \mathrm{L}$ of de-ionized formamide in a $0.5 \mathrm{~mL}$ sample tube, and were denatured at 99 ${ }^{\circ} \mathrm{C}$ for $3 \mathrm{~min}$. The denatured samples were analyzed by capillary electrophoresis on an automated DNA sequencer (ABI/Prism 310; Perkin-Elmer-Applied Biosystems). Electropherograms were scored manually, and only heavy peaks (with signal height above $10 \%$ of the maximum observed at the electropherogram) with sizes ranging from 50 to $350 \mathrm{bp}$ were considered. Fragments of the same size in different genotypes were considered to be the same allele.

The proportion of polymorphic markers detected by each primer combination was obtained by dividing the number of polymorphic fragments by the total number of amplified fragments. The probability of obtaining a different marker phenotype between two random lines for a given AFLP (Power of Discrimination) was calculated as $\mathrm{PD}_{\mathrm{m}}=1-\left(\mathrm{p}_{\mathrm{a}}{ }^{2}+\mathrm{p}_{\mathrm{p}}{ }^{2}\right)$, where $\mathrm{p}_{\mathrm{a}}$ and $\mathrm{p}_{\mathrm{p}}$ are the frequency of absence and presence of the amplified fragment, respectively (de Riek et al., 2001). The power of discrimination of a primer combination was estimated as $\mathrm{PD}_{\mathrm{c}}=1-\Sigma \mathrm{P}_{\mathrm{i}}^{2}$, where $\mathrm{P}_{\mathrm{i}}$ is the frequency of the ith fragment pattern given by that primer combination (Russell et al., 1997).

Polymorphic peaks, scored as either present (1) or absent (0), were used to construct a binary matrix. The genetic similarity (GS) between pairs of cultivars was estimated with the Jaccard coef- ficient (Jaccard, 1908) using the NTYSpc v.2.1 program (Rohlf, 1994) with the SimQual procedure. Adendrogram was constructed using the Unweighted Pair Group Method Average (UPGMA) clustering and drawn with the Molecular Evolutionary Genetics Analysis (MEGA) program, v.2.1 (Kumar et al., 1993).

\section{Results}

AFLP POlyMorPhism. The nine AFLP primer combinations yielded 297 scorable fragments, 47 of them polymorphic in the sample of cultivars studied. The number of polymorphic peaks per primer pair varied from two for $\mathrm{C} 41$ to nine for $\mathrm{C} 26$, with an average of 5.2. The proportion of polymorphic peaks per primer combination ranged from 0.06 (C41) to 0.38 (C26), being 0.16 over all loci (Table 2).

Fragment frequencies had a relatively uniform distribution, with an average of 0.56 per locus (data not shown). Four percent of them had a frequency lower than 0.1 (rare peaks) and $15 \%$ higher than 0.9 (nearly fixed peaks). The number of different patterns or phenotypes amplified by an AFLP primer pair ranged from five (C41) to 95 (C26) with frequencies between 0.01 to 0.59 , and $91 \%$ of them with values lower than 0.1 . The $\mathrm{PD}_{\mathrm{m}}$ ranged from 0.06 for C3B-66 (present in 97\% of the cultivars) to the maximum possible 0.50 (C8B-109, C25-103, C25-192, C26-304 and C3B-128 amplified in 50\% of the cultivars) (data not shown). $\mathrm{PD}_{c}$ values ranged from 0.60 (C41) to 0.98 (C26), with an average of 0.84 .

Cultivar identification. All together, 196 different genotypes (93\% of 210 analyzed) were identified using nine primer combinations. One hundred and eighty-seven cultivars (89\%) had a unique pattern, and the 23 remaining were distributed into nine groups, six with two cultivars, two with three and one with five. Removing all but one of the known mutants of each group from the analysis, the percentage of cultivars individually distinguished increased to 94\% (191 out of 203). Primer combinations C26, C3B and C29 (23 AFLPs) were together able to distinguish 187 (89\%) different genotypes, 173 individually and the remaining distributed among 14 groups, the largest with five cultivars. The other six primers were much less informative, but each identified at least one more cultivar when added to any combination of the others.

Peaches 'Starcrest', 'Early Maycrest', 'Springbelle', 'Spring Lady' and 'Queen Lady' had the same AFLP phenotype. 'Starcrest' is a 'Springcrest' mutant and 'Early Maycrest' is a mutant of 'Maycrest', also a 'Springcrest' sport (Okie, 1998). However,

Table 2. Variability parameters of nine AFLP primer combinations in 210 Prunus persica cultivars.

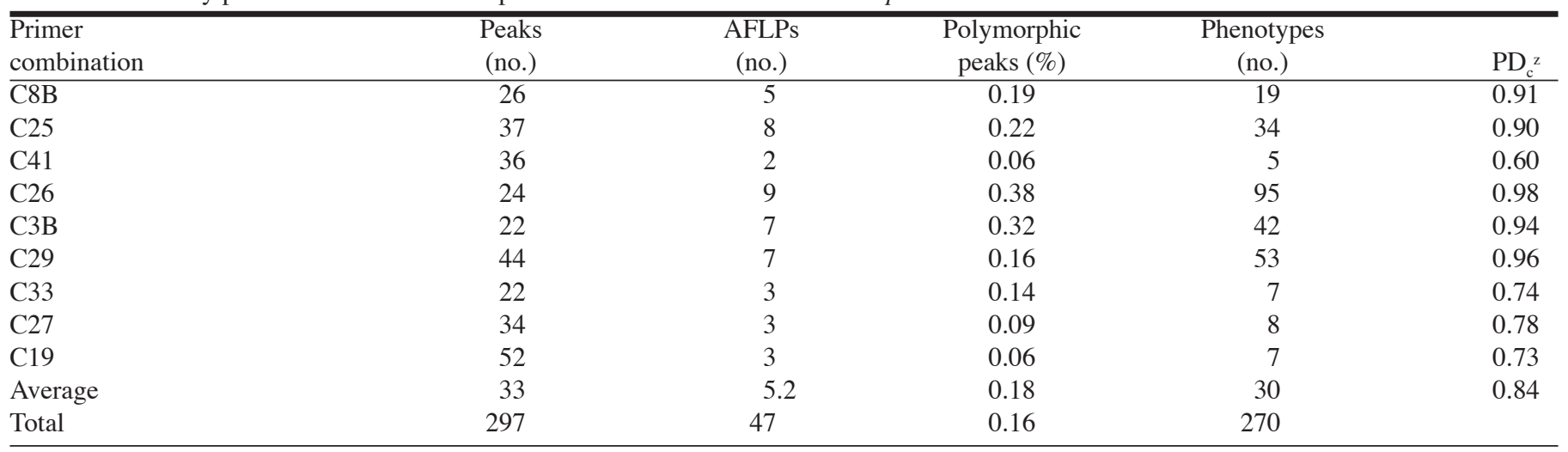

${ }^{2} \mathrm{PD}_{c}=$ Power of discrimination of the primer combination. 


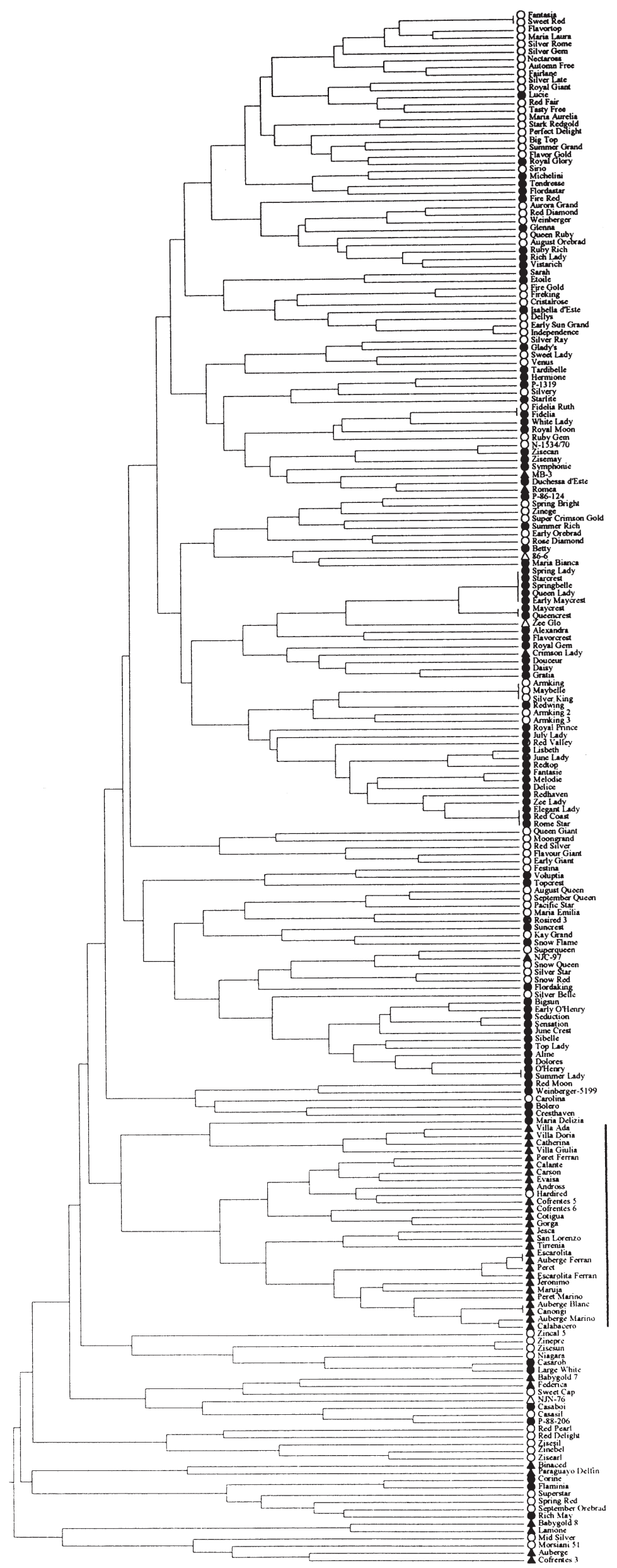

'Maycrest' and one of its mutants, 'Queencrest', which had the same AFLP fingerprint, differed from 'Starcrest' and 'Early Maycrest' at three AFLP loci (C26-138, C26140 and C19-215). 'Springbelle' and 'Spring Lady' come from unknown parents and the origin of 'Queen Lady' ('July Lady' $x$ ' $59-125$ ') is independent from the 'Springcrest' group.

AFLP markers also gave an identical fingerprint between the sport mutations 'Fidelia' and 'Fidelia Ruth', 'O'Henry' and 'Summer Lady', and 'Armking', 'Silver King' and 'Maybelle'. For the five remaining groups of cultivars with identical marker profile: 'Escarolita' and 'Auberge Ferran', 'Auberge' and 'Canongi', 'Fantasia' and 'Sweet Red', and 'Elegant Lady', 'Red Coast' and 'Rome Star' either there is no pedigree information or the available data suggests an independent origin from sexual reproduction.

Jaccard's genetic similarities ranged from 0.13 between the nectarines 'Snowred' and 'Zisearl', to 1 for pairs of cultivars with identical fingerprint with an average similarity value of 0.51 . UPGMA analysis distributed the cultivars into different clusters (Fig.1). Although in general we could not identify clusters of cultivars having the same geographical origin or fruit characteristics, an important exception was a cluster that included most (27) of the 43 nonmelting cultivars.

Some cultivars with related pedigrees were located at close positions in the dendrogram. Selfed parents grouped with their offspring, for example, 'Stark Redgold' with 'Maria Aurelia' and 'Flavortop' with 'Maria Laura', cultivars obtained from open pollination with their known parent such as 'VillaAda', 'Villa Doria' and 'Villa Giulia' with 'Catherina', 'Early O'Henry' with 'O'Henry', 'Vista Rich' with 'Rich Lady' and 'Red Valley' with 'Elegant Lady', and also some of the progeny derived from the same cross, such as 'August Queen' and 'September Queen', 'June Lady' and 'Lisbeth', 'Pacific Star' and 'Maria Emilia' or 'Fidelia' and 'White Lady'.

\section{Discussion}

AFLP analysis was very efficient for the detection of molecular polymorphism in peach. The number of polymorphic loci per assay (5.2) was higher with AFLPs compared to other types of markers: Messeguer et al. (1987) found only four polymorphic enzyme systems out of 13 assayed ( 0.31 polymorphic loci per assay), Warburton and Bliss (1996) detected 1.8RAPDs per reaction, Quarta et al. (2000) found 0.6 polymorphic markers per RFLP assay and Aranzana et al. (2003) obtained one polymorphic locus per SSR reaction. Consequently, the average value of $\mathrm{PD}$ per primer combination $\left(\mathrm{PD}_{\mathrm{c}}=0.84\right)$ was higher than that reached with other markers in peach such as microsatellites with $\mathrm{PD}=0.64$ (Aranzana et al., 2003). A preliminary selection of primer combinations will provide greater efficiency, since the three primer combinations with higher $\mathrm{PD}_{\mathrm{c}}$ values distinguished

Fig. 1. UPGMA (unweighted pair group method average) dendrogram of 210 peach (Prunus persica) cultivars based on their variation at 47 AFLP loci. Peach (melting flesh); $\bigcirc$ Nectarine (melting); Peach (nonmelting); $\Delta$ Nectarine (nonmelting). * Group with most of nonmelting cultivars. 


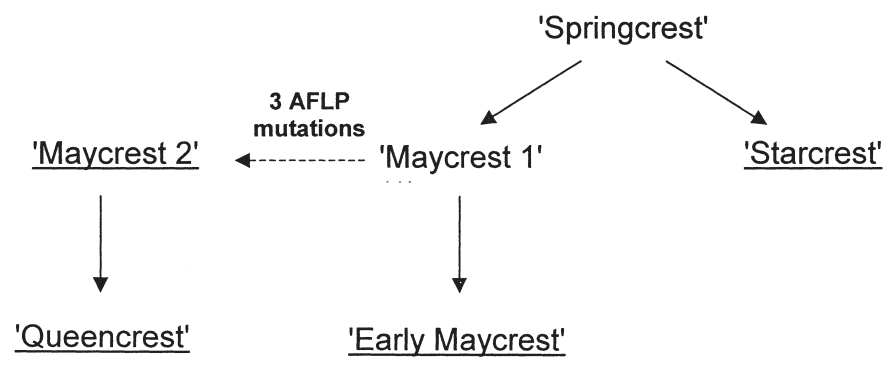

Fig. 2. Proposed origin of the cultivars of the 'Springcrest' sport family analyzed in this paper. The cultivars underlined were those used (supposedly in the case of 'Maycrest 2') herein.

individually $87 \%$ of nonsport cultivars, while each extra primer combination added to the analysis was almost non informative.

Compared with our results, Lu et al. (1998) detected a higher number of scorable fragments per primer combination when studying AFLP markers for map construction in peach: an average of 60 fragments with $E c o \mathrm{RI}+3 / M s e \mathrm{I}+3$ and 114 with $E c o \mathrm{RI}+2 / M s e \mathrm{I}+3$, versus the 31 and 52 that we found. Moreover, for the common EcoRI+AG/MseI+CAA primer combination they found 89 fragments whereas we detected only 52 . Discrepancies may be due to differences in assay conditions or in the criteria (peak intensity and size range) for accepting the presence of an amplified fragment. This also indicates that comparisons of AFLP data among different laboratories may require the establishment of common protocols and interpretation criteria.

Within the cultivars studied there were four groups of known mutants. AFLP patterns among the members of three of them were identical, i.e., 'Fidelia Ruth' and 'Fidelia', 'Summer Lady' and 'O'Henry' and 'Silver King', Maybelle' and 'Armking'. The fourth group of mutants includes 'Maycrest', 'Starcrest' (both 'Springcrest' mutants), 'Early Maycrest' and 'Queencrest' (both mutations from 'Maycrest'). 'Maycrest' and 'Queencrest' had the same fragment pattern, as did 'Early Maycrest' and 'Starcrest', but these two pairs of cultivars differed at three AFLP loci. Then, 'Early Maycrest' and 'Starcrest', with the same AFLP phenotype, have originated as sports from clones that we found to differ for these markers. One possible explanation of these results is the existence of two 'Maycrest' clones, one ('Maycrest 1') identical to 'Starcrest' (and presumably to 'Springcrest'), and one ('Maycrest 2 ') derived from 'Maycrest 1 ' and differing from it at these three AFLPmutations (Fig. 2). 'Queencrest' would have been generated from 'Maycrest 2' (the clone analyzed in this paper), whereas 'Early Maycrest' would have been generated from 'Maycrest 1'. These results indicate that mutations not only occur in AFLP markers among sports, as already reported in peach (Dirlewanger et al., 1998) and in other species such as grapevine (Cervera et al., 1998) or bermudagrass (Zhang et al., 1999), but that these mutations can also be found between different individuals of a sport. SSR mutations were also detected in the 'Springcrest' sport family by Testolin et al. (2000) and by Aranzana et al. (2003), suggesting that this may be a particularly mutable genotype.

Apart from known mutants, some cultivars (generally with unknown pedigree) could not be individually distinguished. Such is the case for 'Springbelle', 'Spring Lady' and 'Queen Lady', all three identical to 'Early Maycrest' and 'Starcrest'. The pedigree of the two former cultivars is not available, and 'Queen Lady' is not closely related to the 'Springcrest' group of mutants. In a previous study (Testolin et al., 2000), 26 SSRs could not discriminate between 'Springbelle' and 'Springcrest'. Aranzana et al. (2002, 2003) found that 'Spring Lady' and 'Queencrest' were identical for 35 SSRs and that 'Springbelle' had the same genotype for 16 SSRs as other members of the 'Springcrest' sport family. This suggests that both 'Springbelle' and 'Spring Lady' (obtained in 1985 and 1981, respectively) could be sport mutations of 'Springcrest' or one of its mutants, most of them obtained before. For 'Queen Lady', analysis of its putative parents with codominant markers such as SSRs may provide additional evidence of its origin.

Yellow flesh peaches 'Red Coast', 'Elegant Lady' and 'Rome Star' had an identical AFLP profile. Marker identity between these three cultivars was detected in the 16 SSRs studied by Aranzana et al. (2003). 'Elegant Lady' and 'Rome Star' were also found to have the same marker fingerprint using 132 RAPD primers (Vinatzer et al., 1999) and with 27 SSRs (Testolin et al., 2000), strongly supporting that 'Rome Star' and 'Red Coast' (both obtained in Italy in 1993) may be the same cultivar or sport mutations of 'Elegant Lady' (created in 1979). 'Fantasia' and 'Sweet Red' had the same AFLP pattern and the same genotype at 16 SSRs (Aranzana et al., 2003). According to their pedigrees (Okie, 1998), 'Sweet Red' was obtained from a 'Stark Redgold' open pollination (op.), in Italy (1990), whereas 'Fantasia' was developed in 1969 by the USDA in Fresno, Calif., from a cross between 'Gold King' and 'P121-24' ('Redking'op.). The molecular data do not confirm the differences predicted from the pedigree, suggesting that both cultivars may have a much closer origin. Given that our data with AFLPs and those of Aranzana et al. (2003) with SSRs were obtained from the same DNA extract, the identity between 'Red Coast' and 'Elegant Lady', and 'Fantasia' and 'Sweet Red', should be confirmed with DNA obtained from an independent source.

Spanish nonmelting peaches 'Escarolita' and 'Auberge Ferran', and 'Auberge' and 'Canongi', gave identical AFLP phenotypes. These four cultivars have been traditionally cultivated since the nineteenth century in "el Tarragonès", a small region of Catalonia (North-Eastern Spain) (Santos et al., 2001). Based on SSR information (Aranzana et al., 2003), these cultivars were found to be highly homozygous and genetically similar, and the AFLP data confirm their closeness, suggesting that they may have originated from a very narrow gene pool.

Nonmelting flesh cultivars were found to be more variable and genetically different from the rest when using codominant markers such as isozymes (Messeguer et al., 1987) or SSRs (Aranzana et al., 2002, 2003). With AFLPs, most of the members of this group $(64 \%)$ are placed on the same cluster, and the average genetic similarity between melting and nonmelting cultivars $(0.48)$ was smaller than the overall average genetic similarity observed $(0.51)$. Early peach breeding efforts were based on limited germplasm and most of the existing commercial cultivars are derived directly from it (Okie et al., 1985; Scorza and Okie, 1990; Werner and Okie, 1998). In contrast, most of the nonmelting cultivars studied, and particularly those from Spain, are of independent origin and may be an important new source of germplasm useful to reach future breeding goals.

Our results show that AFLPs are powerful markers for the detection and analysis of genetic diversity in peach. With the same set of cultivars, Aranzana et al. (2003) using 16 SSR loci that detected 113 alleles, found a similar level of efficiency for cultivar identification: 95\% (SSRs) and 94\% (AFLPs) of the nonsport cultivars could be individually identified. The groups of cultivars with the same genotype were also generally in agreement. AFLPs were compared with other DNA markers (RFLPs, RAPDs and SSRs) by Powell et al. (1996) in soybean, Russell et al. (1997) in barley and Pejic et al. (1998) in maize, 
and were found to be the most efficient when considering the combination of two characteristics: the number of polymorphic fragments detected in a single amplification reaction, very high in AFLPs, and their level of polymorphism, which was moderate for AFLPs in comparison to highly polymorphic markers like SSRs. There are additional factors to be considered in the use of AFLPs, some of them not favorable. These include dominant expression, a severe limitation for use in pedigree comparisons and other genetic analyses; complexity of the technique, which is greater than that of RAPDs or SSRs; the fact that AFLPs is a patented technology that requires licensing for commercial applications; and the scoring process, which in our experience is more difficult and time consuming than that of SSRs. In spite of these considerations, their value in variability analysis is high, alone or as a complement to other markers, and this may be improved if efforts are carried out to increase the level of knowledge of the markers used here, such as the study of their inheritance and their position in the Prunus genome.

\section{Literature cited}

Aranzana, M.J., J. Garcia-Mas, J. Carbó, and P. Arús. 2002. Development and variability analysis of microsatellite markers in peach. Plant Breeding 121:87-92.

Aranzana, M.J., J. Carbó, and P. Arús. 2003. Microsatellite variability in peach [Prunus persica (L) Batsch.]: Cultivar identification, marker mutation, pedigree inferences and population structure. Theor. Appl. Genet. 106:1341-1352.

Arulsekar, S., D.E. Parffitt, and D.E. Kester. 1986. Comparison of isozyme variability in peach and almond cultivars. J. Hered. 77:272-274.

Byrne, D.H. 1990. Isozyme variability in four diploid stone fruits compared with other woody perennial plants. J. Hered. 81:68-71.

Cervera, M.T., J.A. Cabezas, J.C. Sancha, F. Martínez-de-Toda, and J.M. Martínez-Zapater. 1998. Application of AFLPs to the characterization of grapevine Vitis vinifera L. genetic resources. A case study with accessions from Rioja (Spain). Theor. Appl. Genet. 97:51-59.

de Riek, J., E. Calsyn, I. Everaert, E. Van Bockstaele, and M. De Loose. 2001. AFLP based alternatives for the assessment of distictness, uniformity and stability of sugar beet varieties. Theor. Appl. Genet. 103: 1254-1265.

Dirlewanger,E., S. Duha, M.A. Viruel, and R. Saunier. 1998. Identification of peach varieties using molecular markers. Acta Hort. 465:69-78.

Jaccard, P. 1908. Nouvelles recherches sur la distribution florale. Bul. Soc. Vaudoise Sci. Nat. 44:223-270.

Kumar, S., K. Tamura, and M. Nei. 1993. MEGA: Molecular evolutionary genetics analysis software. version 1.0. Pa. State Univ., Univ. Park, Pa.

Lu, Z.X., B. Sosinski, G.L. Reighard, W.V. Baird, and A.G. Abbott. 1998. Construction of a genetic linkage map and identification of AFLP markers for resistance to root-knot nematodes in peach rootstocks. Genome 41:199-207.
Messeguer, R., P. Arús, and M. Carrera. 1987. Identification of peach cultivars with pollen isozymes. Scientia Hort. 31:107-117.

Okie, W.R., D.W. Ramming, and R. Scorza. 1985. Peach, nectarine and other stone fruit breeding by the USDA in the last two decades. HortScience 20:633-641.

Okie, W.R. 1998. Handbook of peach and nectarine varieties. Agr. Res. Serv., Byron, Ga.

Pejic, I., P. Ajmone-Marsan, M. Morgante, V. Kozumplick, P. Castiglioni, G. Taramino, and M. Motto. 1998. Comparative analysis of genetic similarity among maize inbred lines detected by RFLPs, RAPDs, SSRs and AFLPs. Theor. Appl. Genet. 97:1248-1255.

Powell, W., M. Morgante, C. Andre, M. Hanafey, J. Vogel, S. Tingey, and A. Rafalski. 1996. The comparison of RFLP, RAPD, AFLP and SSR (microsatellite) markers for germplasm analysis. Mol. Breeding 2:225-238.

Quarta, R., M.T. Dettori, I. Verde, U. Marchesi, and A. Palombi. 2000. Characterization and evaluation of genetic diversity in peach germplasm using RAPD and RFLP. Acta Hort. 546:489-496.

Rohlf ,F.J., 1994. NTSYS-pc. version 2.1. Exeter Software, Setauket, N.Y.

Russell, J.R., J.D. Fuller, M. Macaulay, B.J. Hatz, A. Jahoor, W. Powell, and R. Waugh. 1997. Direct comparison of levels of genetic variation among barley accessions detected by RFLPs, AFLPs, SSRs and RAPDs. Theor. Appl. Genet. 95:714-722.

Santos, J., J.M. Aramburu, and I. Batlle, 2001. La recuperació del préssec 'Canonogí'. Catalunya Rural i Agrària 82:19-21.

Scorza, R. and W.R. Okie 1990. Peaches (Prunus), p. 175-231. In: J.R. lington and J.N. Moore (eds.). Genetic resources of temperate fruits and nut crops. Intl. Soc. Hort. Sci., The Netherlands.

Testolin, R., T. Marrazzo, G. Cipriani, R. Quarta, I. Verde, M.T. Dettori, M. Pancaldi, and S. Sansavini. 2000. Microsatellite DNA in peach (Prunus persica (L.) Batsch) and its use in fingerprinting and testing the genetic origin of cultivars. Genome 43:512-520.

Vinatzer, B., M. Pancaldi, and S. Sansavini. 1999. Potenzialità e limiti del "fingerprinting" nell'identificazione varietale del pesco. Frutticoltura 4:97-101.

Viruel, M.A., R. Messeguer, M.C. de Vicente, J. García-Mas, P. Puigdomènech, F. Vargas, and P. Arús. 1995. A linkage map with RFLP and isozyme markers for almond. Theor. Appl. Genet. 91:964-971.

Vos, P., R. Hogers, M. Bleeker, M. Reijans, T. van de Lee, M. Hornes, A. Frijters, J. Pot, M. Kuiper, and M. Zabeau. 1995. AFLP: A new technique for DNA fingerprinting. Nucl. Acids Res. 23:4407-4414.

Warburton, M.L. and F.A. Bliss. 1996. Genetic diversity in peach (Prunus persica $\mathrm{L}$. Batch) revealed by randomly amplified polymorphic DNA (RAPD) markers and compared to inbreeding coefficients. J. Amer. Soc. Hort. Sci. 121:1012-1019.

Werner, D.J. and W.R. Okie. 1998. A history and description of the Prunus persica plant introduction collection. HortScience 33:787-793.

Zhang, L.H., P. Ozias-Akins, G. Kochert, S. Kresovich, R. Dean, and W. Hanna. 1999. Differentiation of bermudagrass (Cynodon spp.) genotypes by AFLP analyses. Theor. Appl. Genet. 98:895-902. 